\title{
SEX DIFFERENCES IN INFLAMMATORY RESPONSE AND ACID-BASE BALANCE IN PREPUBERTAL CHILDREN WITH SEVERE SEPSIS
}

\author{
Nicolas Lefèvre, ${ }^{\star \dagger}$ Benjamin Noyon, ${ }^{\ddagger}$ Dominique Biarent,${ }^{\S}$ Francis Corazza, ${ }^{\dagger}$ \\ Jean Duchateau, ${ }^{\prime \prime}$ and Georges Casimir ${ }^{* \|}$ \\ 'Department of Pulmonology, Allergology and Cystic Fibrosis, Queen Fabiola Children's University \\ Hospital, Free University of Brussels, Brussels, Belgium; ' ${ }^{\dagger}$ Queen Fabiola Children's University Hospital, \\ Free University of Brussels, Brussels, Belgium; ${ }^{\ddagger}$ Department of Emergency Medicine, Queen Fabiola \\ Children's University Hospital, Free University of Brussels, Brussels, Belgium; ${ }^{\S}$ Department of Critical \\ Care Medicine, Queen Fabiola Children's University Hospital, Free University of Brussels, Brussels, \\ Belgium; and "Laboratory of Pediatrics, Free University of Brussels, Brussels, Belgium
}

Received 6 Jun 2016; first review completed 29 Jun 2016; accepted in final form 6 Oct 2016

\begin{abstract}
Purpose and Methods: The severity and prognosis of various acute inflammatory conditions, such as sepsis, differ between males and females. The mechanisms underlying these sex differences probably involve both hormonal and genetic factors. In order to evaluate a possible genetic influence, we reviewed clinical signs and biological inflammatory markers of prepubertal children with severe sepsis admitted to the pediatric intensive care unit (PICU). Findings: A total of 142 prepubertal children, 66 girls and 76 boys, suffering from severe sepsis and admitted to the PICU were included. The survival rate demonstrated a tendency to be higher in females $(P=0.14)$. Maximum white blood cell count $(23,800$ cells $/ \mu \mathrm{L}[15,110-34,600]$ in girls vs. 19,025 cells $/ \mu L[12,358-26,098]$ in boys, $P=0.02)$, neutrophil count $(16,944 \mathrm{cells} / \mu \mathrm{L}[10,620-27,540]$ vs. $13,756 \mathrm{cells} / \mu \mathrm{L}[8410-20,110], P=0.03)$, and C-reactive protein level $(26.2 \mathrm{mg} / \mathrm{dL}$ [15.7-33.6] vs. $18.8 \mathrm{mg} / \mathrm{dL}$ [11.1-30.0], $P=0.04$ ) were all significantly higher in girls. Girls also exhibited significantly longer fever duration ( 2 days [1-6] vs. 1 day [1-3] for the boys, $P<0.01$ ), lower $\mathrm{pH}$ on admission (7.32 [7.25-7.39] vs. 7.37 [7.317.43] $P=0.03$ ), and lower base excess $(-6 \mathrm{mEq} / \mathrm{L}[-10.7$ to -0.8$] \mathrm{vs}$. $-2.3 \mathrm{mEq} / \mathrm{L}[-6.6$ to -2.6$], P<0.01)$, as well as lower bicarbonate levels $(19.1 \mathrm{mEq} / \mathrm{l}[15.9-24.0]$ vs. $21.15 \mathrm{mEq} / \mathrm{l}[18.3-26.68], P=0.04)$, when compared with the boys. Conclusions: Our study revealed higher neutrophilic inflammation, as well as lower pH on admission, in girls with severe sepsis; associated with longer fever duration, which could contribute to better pathogen clearance. However, further studies are needed to demonstrate the link between acidosis and modulation of the immune response.
\end{abstract}

KEYWORDS-Acidosis, gender difference, neutrophilic immune response, pediatric sepsis

\section{INTRODUCTION}

Severe sepsis is commonly defined as a systemic inflammatory response to infection, associated with organ dysfunction (1). Infection triggers a complex and prolonged immune response, provoking in turn proinflammatory and anti-inflammatory mechanisms that, while helping to clear the infection, also cause severe tissue injury (2). It is the reason for a significant number of admissions to intensive care units and a major cause of death (3).

The severity and prognosis of various acute inflammatory conditions, such as sepsis or burn injuries, differ between males and females, with improved clinical course and increased survival rates seen in females $(4,5)$. The mechanisms underlying these sex-dependent differences are multiple and

Address reprint requests to Nicolas Lefèvre, MD, Department of Pulmonology, Allergology, and Cystic Fibrosis, Queen Fabiola Children's University Hospital, Free University of Brussels, Avenue J.J. Crocq 15, B-1020 Brussels, Belgium; E-mail: nicolas.lefevre@huderf.be

NL analyzed and interpreted the data, and drafted the manuscript. BN screened the patients, collected the data, and revised the manuscript. DB participated in the design of the study and helped to collect the data and revise the manuscript. FC participated in the design of the study and helped to draft the manuscript. JD performed the statistical analysis and helped to revise the manuscript. GC conceived of the study, and participated in its design and helped to draft the manuscript. All authors read and approved the final manuscript.

NL received a grant from "The Belgian Kid's Fund."

The authors report no conflicts of interest.

DOI: $10.1097 /$ SHK.0000000000000773

Copyright $\mathbb{C} 2016$ by the Shock Society probably involve both hormonal and genetic factors. Several studies have described the modulating role of sex hormones in both humoral and cell-mediated immune responses during the course of various disease processes. It is commonly understood that the clinical differences between men and women in terms of inflammatory processes may be explained by different levels of sex steroids $(6,7)$. However, recent findings have revealed significant differences in inflammatory markers between prepubertal boys and girls suffering from acute or chronic inflammatory diseases $(8,9)$. The sex hormone levels are very low in this population compared with adults, most likely insufficient to account for the differences observed during inflammatory conditions between males and females from neonates to the elderly, thus suggesting another origin $(10,11)$.

Several proteins involved in immunity are encoded on the $\mathrm{X}$ chromosome. The genes of certain principal protein members

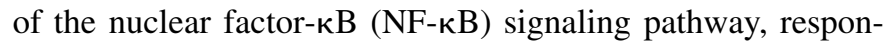
sible for the production of pro-inflammatory cytokines such as interleukin (IL)-6, are linked to the $\mathrm{X}$ chromosome, namely IL-1 receptor-associated kinase $1, \mathrm{NF}-\kappa \mathrm{B}$ essential modulator, and Bruton tyrosine kinase (12).

Females carry two $\mathrm{X}$ chromosomes, one of which is randomly inactivated during early embryogenesis to maintain the dosage balance of proteins across both sexes (13). Females are thus composed of a mosaic of cells, with genes from either the paternal or maternal $\mathrm{X}$ chromosome, providing them with 
greater diversity to fight against infectious attacks (14). Moreover, up to $15 \%$ of $\mathrm{X}$-linked genes escape inactivation to some degree, increasing the X-linked cellular protein content in females compared with that of males (15). Therefore, polymorphisms of X-linked genes and cellular mosaicism in females could be responsible for some of the specific responses of either sex to inflammation and help explain the lower mortality reported in females with septic shock.

In order to confirm the differences we observed between males and females in prepubertal children with acute inflammatory processes, supporting a genetic origin rather than a sex steroid influence, we studied clinical and biological inflammatory markers in a cohort of prepubertal children with severe sepsis admitted to the pediatric intensive care unit (PICU).

\section{PATIENTS AND METHODS}

We reviewed the clinical data of all prepubertal children (girls aged 0-11 years; boys aged 0-12) admitted to the PICU of our hospital who were diagnosed with severe sepsis, from January 2000 to December 2013. Severe sepsis was defined according to the criteria of the Surviving Sepsis Campaign $(1,2)$.

The exclusion criteria were as follows: congenital or acquired immunodeficiency including immunosuppressive drugs; hematopoietic stem cell transplantation; immunoglobulin therapy; extracorporeal membrane oxygenation (ECMO).

For each patient, sex, age, medical history, pediatric index of mortality 2, pediatric risk of mortality, survival, length of stay in the PICU, duration of antimicrobial therapy, and blood cultures were all recorded in an Excel database for Mac, Version 2011 (Microsoft, Wash). The following information was collected from each patient on admission to the PICU and at 24, 48, 72, 96, and $120 \mathrm{~h}$ after admission: body temperature, C-reactive protein (CRP) level, hemoglobin level, white blood cell count (WBC), neutrophil count, monocyte count, platelet count, blood $\mathrm{pH}$, blood gas level, lactic acid level, base excess level, bicarbonate level, arterial blood pressure, heart rate, respiratory rate, pulsed oxygen saturation, and doses of dobutamine, dopamine, adrenaline, noradrenaline, and milrinone administered

The study was approved by the Ethics Committee of the Hôpital Universitaire des Enfants Reine Fabiola and was in adherence to the tenets of the Declaration of Helsinki. All the patients admitted to the PICU of our hospital were informed that their medical data could be used for research purposes but consent was not required by the Ethics Committee, since data were collected anonymously.

\section{Statistical analysis}

As the continuous variables did not exhibit normal distribution, nonparametric tests were used for statistical analysis. The results have been expressed as median \pm interquartile range for $\mathrm{n}$ independent patients. Correlations between continuous variables were tested using the Spearman rank test. To evaluate differences between the sexes, the boys and girls were compared using the Mann-Whitney test for independent groups. Differences in the distribution of discrete variables between the groups were assessed using Fisher exact test or the chi-squared test. Differences were considered statistically significant when $P$ was $<0.05$. Calculations were performed using GraphPad Prism statistical software Version 6.00 for Mac (GraphPad Software, San Diego, Calif).

\section{RESULTS}

\section{Patients}

Over 2,009 patients were screened for sepsis during their hospital stay, with 201 diagnosed with severe sepsis. A total of 15 were post-pubertal (10 girls and 5 boys), 28 were treated with ECMO (10 girls and 18 boys), and 16 presented with immunodeficiency ( 6 girls and 10 boys). A total of 142 patients (66 girls and 76 boys) met the inclusion criteria.
TABLE 1. Distribution of comorbidities between girls and boys

\begin{tabular}{lccc}
\hline Comorbidity & Girls $(\mathrm{n}=66)$ & Boys $(\mathrm{n}=76)$ & $P^{*}$ \\
\hline Congenital heart disease & 16 & 23 & 0.45 \\
Polymalformative syndrome & 4 & 3 & 0.70 \\
Prematurity & 4 & 1 & 0.19 \\
Allergy & 3 & 2 & 0.66 \\
Cerebral palsy & 2 & 3 & 1.00 \\
Asthma & 2 & 2 & 1.00 \\
Esophageal atresia & 3 & 1 & 0.34 \\
Urinary tract malformation & 3 & 0 & 0.10 \\
Necrotizing enterocolitis & 2 & 0 & 0.22 \\
Sickle cell disease & 0 & 2 & 0.50 \\
Intussusception & 1 & 0 & 0.47 \\
Congenital diaphragmatic hernia & 0 & 1 & 1.00 \\
Type la glycogen storage disease & 0 & 1 & 1.00 \\
G6PD deficiency & 0 & 1 & 1.00 \\
Hemophilia A & 0 & 1 & 1.00 \\
\hline
\end{tabular}

${ }^{*}$ Fisher exact test or chi-squared test.

G6PD indicates glucose-6-phosphate dehydrogenase.

\section{Clinical parameters}

We observed no significant differences in terms of age (17 months [5-80] for boys vs. 38 months [12-114] for girls, $P=0.06$ ), comorbidities (Table 1) or origin of the sepsis (Table 2) between the sexes. Following antibiotic therapy, the girls exhibited a longer duration of fever in comparison with the boys ( 2 days [1-6] vs. 1 day [1-3], respectively, $P<0.01)$ (Fig. 1). The duration of intravenous antibiotic therapy and blood cultures results were similar between males and females (Fig. 2).

Neither were there any differences in the length of stay in the PICU or the gravity scores. Boys displayed a tendency toward higher mortality, although this difference was not statistically significant (24\% mortality rate for boys vs. $13 \%$ for girls, $P=0.14$ ) (Fig. 3).

The respiratory and hemodynamic parameters did not significantly differ between the sex neither did the doses of catecholamine administered.

\section{Biological parameters}

Maximum WBC was higher in girls $(23,800$ cells $/ \mu \mathrm{L}$ $[15,110-34,600])$ than boys $(19,025$ cells/ $\mu \mathrm{L}$ [12,358$26,098], P=0.02$ ), with a tendency to be the highest on the

TABLE 2. Distribution of the origin of sepsis between girls and boys

\begin{tabular}{lccc}
\hline Comorbidity & Girls $(\mathrm{n}=66)$ & Boys $(\mathrm{n}=76)$ & $P^{*}$ \\
\hline Meningococcemia & 20 & 18 & 0.45 \\
Cardiac surgery & 10 & 16 & 0.39 \\
Meningitis & 8 & 12 & 0.63 \\
Pneumonia & 6 & 9 & 0.79 \\
Catheter related & 4 & 7 & 0.54 \\
Toxic shock syndrome & 4 & 6 & 0.75 \\
Peritonitis & 6 & 2 & 0.15 \\
Urinary tract infection & 5 & 2 & 0.25 \\
Digestive surgery & 1 & 2 & 1.00 \\
Necrotizing enterocolitis & 2 & 0 & 0.22 \\
Burn injury & 0 & 1 & 1.00 \\
Mediastinitis & 0 & 1 & 1.00 \\
\hline
\end{tabular}

*Fisher exact test or chi-squared test. 
A

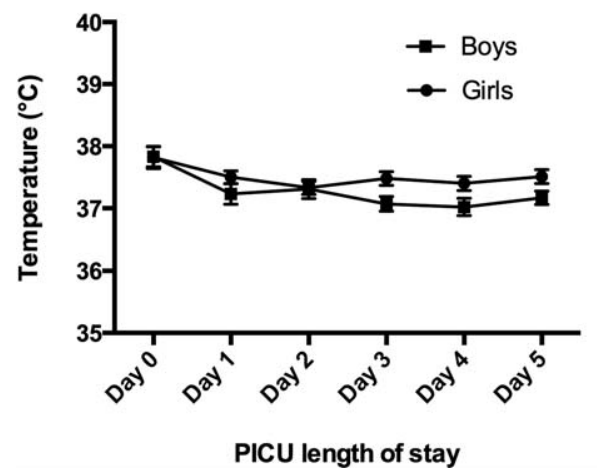

B

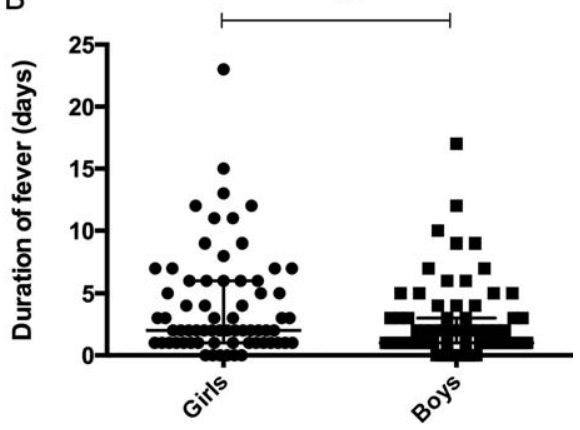

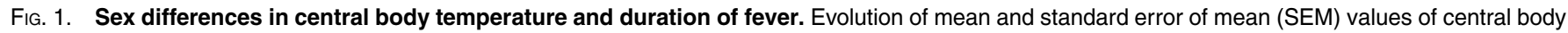

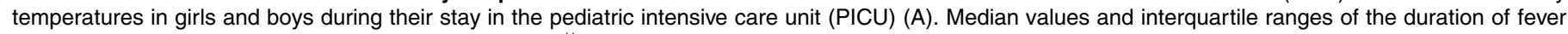
$\left(>38.0^{\circ} \mathrm{C}\right)$ after antibiotic therapy in girls and boys $(\mathrm{B}) .{ }^{\star \star} P<0.01$ using the Mann-Whitney test.

fourth day (Fig. 4). We observed the same difference in girls in terms of maximum neutrophil count $(16,944$ cells/ $\mu \mathrm{L}[10,620$ $27,540]$ vs. $13,756 \mathrm{cells} / \mu \mathrm{L} \quad[8,410-20,110]$ for boys, $P=0.03)$, especially on the third day $(11,734$ cells $/ \mu \mathrm{L}$ $[6,043-19,211]$ vs. $6,364 / \mu \mathrm{L}[4,595-12,683]$ for boys, $P<0.01$ ) (Fig. 5).

Maximum CRP levels were also significantly higher in girls $(26.2 \mathrm{mg} / \mathrm{dL}$ [15.7-33.6]) compared with boys $(18.8 \mathrm{mg} / \mathrm{dL}$ [11.1-30.0], $P=0.04$ ), with a tendency to be the highest on the second day $(P=0.07)$ (Fig. 6). We observed no differences between the groups for hemoglobin, platelet, or monocyte levels.

\section{Metabolic parameters}

On admission to the PICU, girls exhibited lower base excess in comparison with boys $(-6 \mathrm{mEq} / \mathrm{L}[-10.7$ to -0.8$]$ vs. -2.3 $\mathrm{mEq} / \mathrm{L}[-6.6$ to -2.6$], P<0.01)$, as well as lower bicarbonate levels (19.1 mEq/L [15.9-24.0] vs. $21.15 \mathrm{mEq} / \mathrm{L}$ [18.3-26.68], $P=0.04)$. Girls also displayed lower $\mathrm{pH}$ than boys on admission (7.32 [7.25-7.39] vs. 7.37 [7.31-7.43], $P=0.03$ ) (Fig. 7). These differences disappeared 1 day after PICU admission. We found no other significant differences in metabolic parameters.

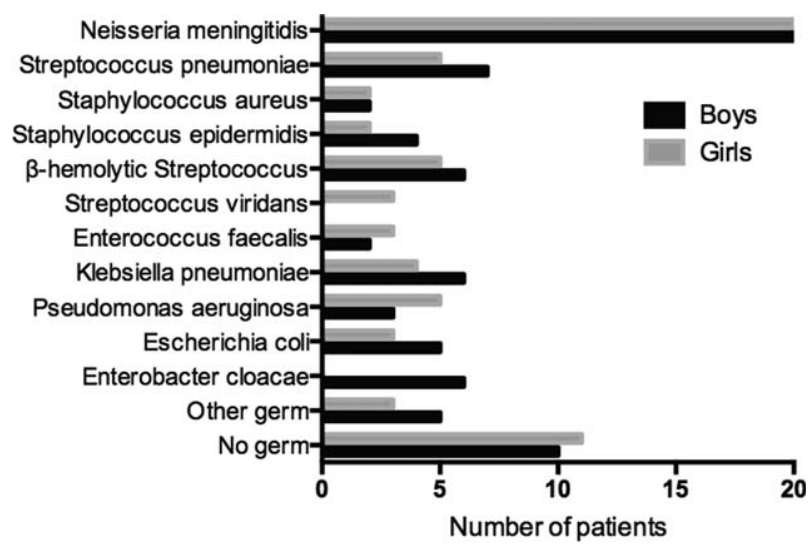

FIG. 2. Distribution of germs in blood cultures of girls and boys.

\section{DISCUSSION}

This retrospective study involving prepubertal children with severe sepsis revealed several clinical and biological differences between girls and boys that we had already observed in other acute inflammatory processes (8).

Girls with severe sepsis exhibited a longer duration of fever in comparison with the boys after admission. The use of antipyretic drugs could be the source of this sex difference. However, all patients in PICU received same doses per kilogram of body weight of antipyretic drugs and, acetaminophen and ibuprofen are equally metabolized in boys and girls (16). An explanation could be the receptor activator of nuclear factor kappa-B (RANK) and its ligand, which have been shown to mediate sex-specific thermoregulation in inflammation. Genetic inactivation of RANK alters physiological thermoregulation in female mice which seems to be regulated, only in part, by ovarian sex hormones (17).

Girls also presented higher levels of white blood cells, especially neutrophils, in comparison with boys. One of the major neutrophil chemoattractants is IL-8, which is produced in response to NF- $\mathrm{KB}$ activation (18). In a previous study, higher IL-8 secretion was found in females in response to in vitro stimulation with lipopolysaccharide (LPS), which may explain the higher neutrophil count observed in girls (19). IL-8 seems to play a crucial role in pediatric sepsis as high levels of serum

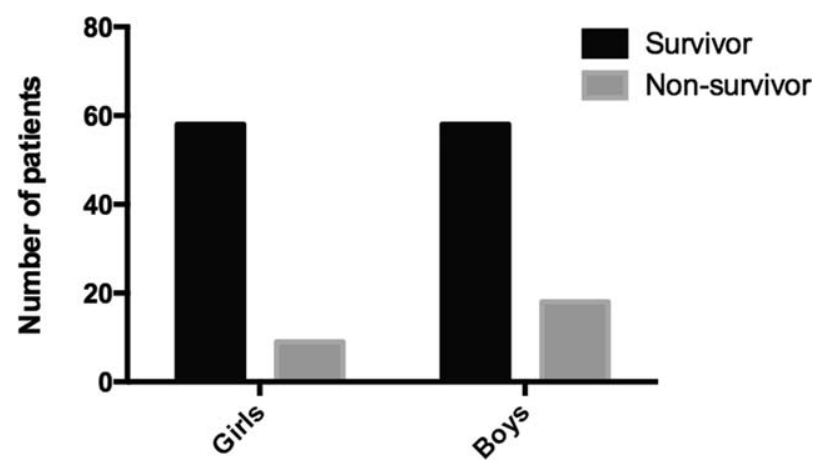

FIG. 3. Mortality rates for girls and boys. 

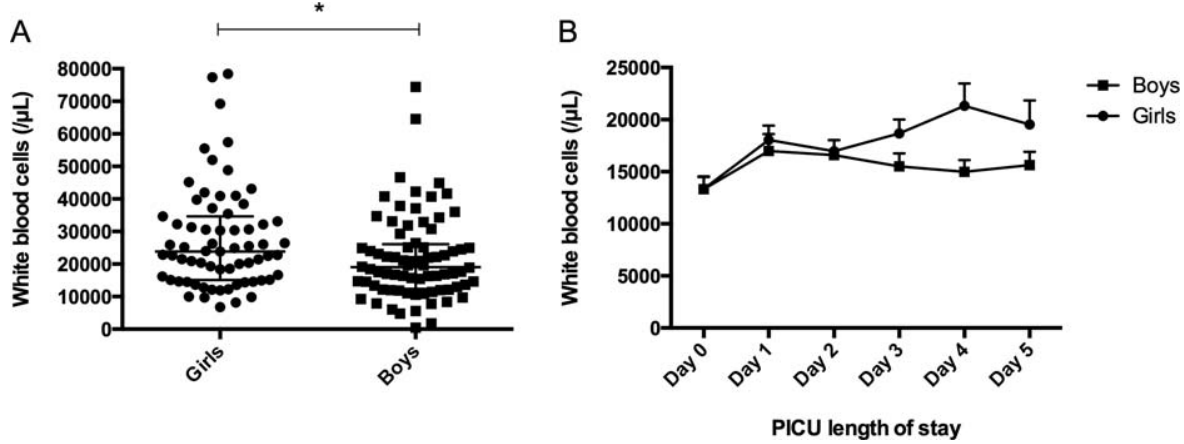

FIG. 4. Sex differences in the white blood cell count. Median values and interquartile ranges of the maximum white blood cell counts for girls and boys (A). Evolution of mean and standard error of mean (SEM) values of the white blood cell counts for boys and girls during their stay in the pediatric intensive care unit (PICU) (B). ${ }^{*} P<0.05$ using the Mann-Whitney test.

IL-8 were a strong negative predictor for 28-day mortality in children younger than 10 years with septic shock (20). It is interesting to note that the difference in neutrophil counts became significant on the third day after admission, corresponding to the mean generation time of myelocytes, thus situating the origin of the difference in the bone marrow rather than the marginated pool of neutrophils (21). The kinetic curve also showed a tendency toward a difference on the fourth and fifth days, which would probably become significant with a higher number of patients. In a previous in vitro study, we observed a different kinetic between males and females in terms of inflammatory cytokine production in whole blood stimulated with endotoxin, which could explain this sex difference only on the third day (22). Polymorphisms of the gene encoding for the Wiskott-Aldrich syndrome protein, located on the $\mathrm{X}$ chromosome and responsible for X-linked severe congenital neutropenia, could be involved in this difference (23).

As already observed in both children and adults, CRP levels were also significantly higher in girls compared with boys, with a tendency toward achieving the highest levels on the second day $(8,9,24)$. The CRP level peaked on the second day, the approximate time when de novo cellular synthesis of CRP is maximal (25). CRP is primarily produced by hepatocytes under transcriptional control by IL- 6 . IL- 6 is secreted in response to the activation of the NF- $\mathrm{B}$ signaling pathway by pathogen-associated molecular patterns through Toll-like receptors (TLRs) (26). This intracellular pathway, which induces the secretion of other pro-inflammatory cytokines, such as IL-8 and tumor necrosis factor (TNF)- $\alpha$, involves several proteins encoded on the $\mathrm{X}$ chromosome. The sex-related differences we observed in terms of both the production of CRP through IL-6 and recruitment of neutrophils by IL-8 induction could thus be related to polymorphisms of X-linked genes of the TLR signaling pathway, in addition to cellular mosaicism in females (12). Given the age of our patients, it is unlikely that sex steroids play a significant role in these sex differences. Measurement of the IL-6 levels as well as the levels of other pro-inflammatory cytokines such as IL-1 $\beta$, IL-8, and TNF- $\alpha$ would help to confirm the implication of the TLRs and the potential genetic origin to the sex differences we observed. However, in an in vitro study, pro-inflammatory cytokine production (IL-1 $\beta$ and IL-6) after stimulation of whole blood with lipopolyscharride was higher in males compared with females, and Turner patients followed the same pattern of reactivity as males (22). In our study, as CRP levels were higher in girls compared with boys, we would expect increased IL-6 secretion in girls as a result. Most in vitro studies show higher inflammatory cytokine secretion in males compared with females, while in vivo studies reveal contradictory results with a higher inflammatory response in males and females on occasion $(19,27)$. These discrepancies illustrate the numerous
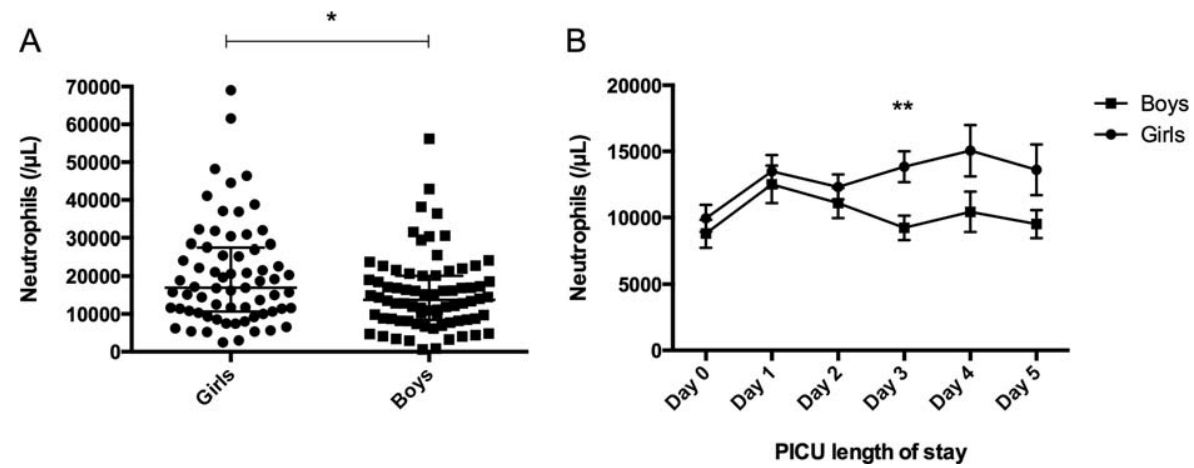

FIG. 5. Sex differences in the neutrophil count. Median values and interquartile ranges of maximum neutrophil counts for girls and boys (A). Evolution of mean and standard error of mean (SEM) values of the neutrophil counts for girls and boys during their stay in the pediatric intensive care unit (PICU) $(B) .{ }^{\star} P<0.05$, ${ }^{*} P<0.01$ using the Mann-Whitney test. 

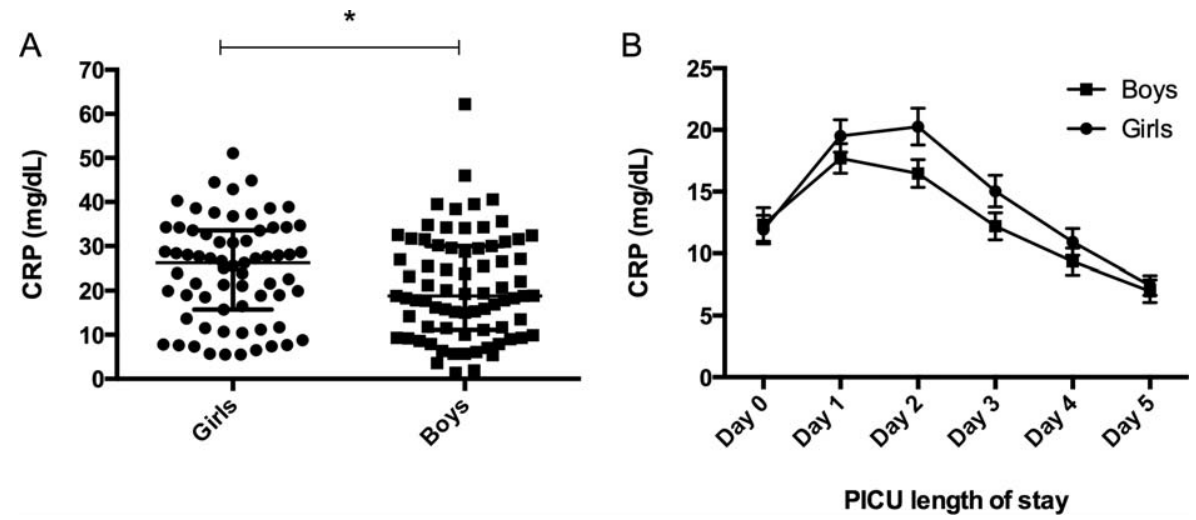

FIG. 6. Sex differences in the level of C-reactive protein. Median values and interquartile ranges of the maximum levels of C-reactive protein (CRP) for girls and boys (A). Evolution of mean and standard error of mean (SEM) values of CRP levels for girls and boys during their stay in the pediatric intensive care unit (PICU) (B). ${ }^{*} P<0.05$ using the Mann-Whitney test.

and complex interactions occurring between the immune system and other organs.

Girls appeared to exhibit a more pronounced neutrophilic inflammatory response and longer-lasting fever, associated with a tendency toward higher temperatures, probably due to a distinct innate immune response or the different sensitivity of their receptors in comparison with boys. The higher level of circulating neutrophils in girls could also contribute to better pathogen clearance during the early inflammatory response (18), consequently improving their survival of sepsis (11). Our findings were strengthened by the absence of confounding factors, such as age, pathogen, medical history, or duration of the sepsis before admission, which were all similar between the groups.

Although the patients included were prepubertal, estrogen levels of healthy prepubertal girls can be eight times higher than those of prepubertal boys (10) and sex differences in both the incidence and the mortality of sepsis are observed in the neonatal period also. However, sex hormones levels in prepubertal children are still very low compared with adults and probably insufficient to explain the sex differences observed in inflammatory conditions from neonates to the elderly (11). Likewise, unpublished data of our group did not show any differences between prepubertal boys and prepubertal girls in

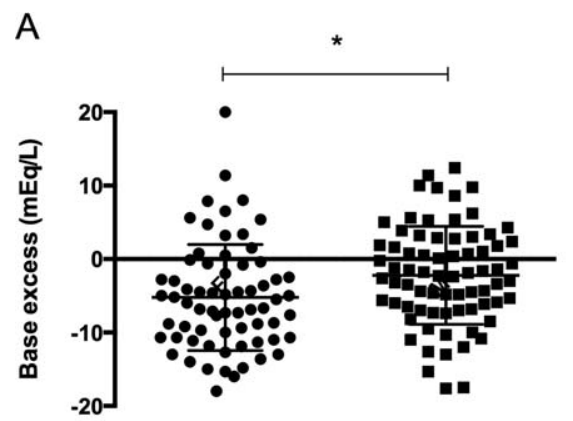

C

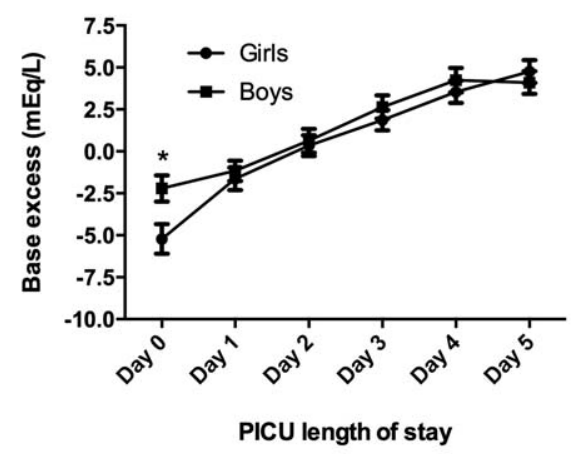

B

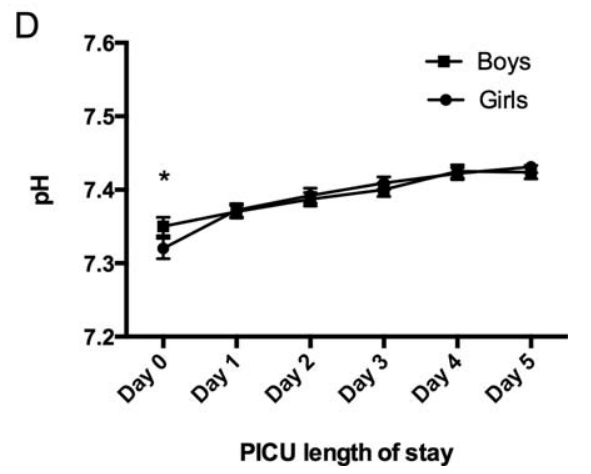

FIG. 7. Sex differences in base excess and pH. Median values and interquartile ranges of base excess (A) and pH (B) on admission in girls and boys. Evolution of mean and standard error of mean (SEM) values of base excess (C) and $\mathrm{pH}(\mathrm{D})$ in girls and boys during their stay in the $\mathrm{PICU}$. ${ }^{*} P<0.05$ using the Mann-Whitney test. 
inflammatory cytokine production in response to LPS, when blood was incubated with increasing concentrations of $17 \beta$-estradiol.

To our knowledge, this is the first study describing a sexrelated difference in the acid-base balance of children with sepsis. We observed a significantly lower $\mathrm{pH}$ associated with a higher base deficit in girls compared with boys on admission to the PICU. This higher base deficit was not linked to higher lactate production, however, and tended to rapidly disappear on initiating fluid management and respiratory support. Nevertheless, this higher acidity could enhance the inflammatory response in girls by increasing the expression of adhesion molecules at the surface of leukocytes and the secretion of pro-inflammatory cytokines.

The $\mathrm{pH}$ of the extracellular milieu influences a wide range of immunological functions (28). In vitro studies have revealed the following associations: increased secretion of inflammatory cytokines, such as IL-1 $\beta$, IL- 6 , or TNF- $\alpha$ by mononuclear cells; neutrophil activation characterized by an up-regulation of cluster of differentiation (CD)18 expression and hydrogen peroxide production; maturation of human dendritic cells (29, 30). Recently, a positive correlation between strong anion gap and IL-6, IL-8, IL-10, and TNF- $\alpha$ plasma concentrations was found in critically ill patients (31). Most of the prognostic factors for septic patients are evaluated on admission indicating the importance of the initial response in the course of the disease (32). Among this initial response, innate immune system, mainly based on phagocytes, seems to play a crucial role. Therefore, a modulation of the early inflammatory process by metabolic acidosis, before initiating the hemodynamic management and respiratory support, could influence the response to sepsis (33).

\section{CONCLUSIONS}

Our study, although retrospective in nature, confirmed our previous clinical observations of children with other acute inflammatory processes, demonstrating a stronger inflammatory response in girls compared with boys, specifically involving neutrophils. The more acidic environment reported in girls on admission could contribute to the elevated neutrophil recruitment and pro-inflammatory cytokine secretion, helping girls to clear infection more efficiently than boys. The patient age of this cohort is not indicative of there being a link to sex hormones, to account for the sex differences we described in the inflammatory response to severe sepsis, suggesting another origin. However, a prospective study including dosage of TLR-mediated inflammatory cytokines is needed to suggest a genetic factor involving X-linked genes of the NF- $\mathrm{BB}$ signaling pathways and confirm the modulation of the neutrophil response by extracellular acidosis.

\section{REFERENCES}

1. Dellinger RP, Levy MM, Rhodes A, Annane D, Gerlach H, Opal SM, Sevransky JE, Sprung CL, Douglas IS, Jaeschke R, et al.: Surviving sepsis campaign: international guidelines for management of severe sepsis and septic shock: 2012 . Crit Care Med 41(2):580-637, 2013.

2. Angus DC, van der Poll T: Severe sepsis and septic shock. $N$ Engl J Med 369(9):840-851, 2013.
3. Watson RS, Carcillo JA, Linde-Zwirble WT, Clermont G, Lidicker J, Angus DC: The epidemiology of severe sepsis in children in the United States. Am J Respir Crit Care Med 167(5):695-701, 2003.

4. Barrow RE, Herndon DN: Incidence of mortality in boys and girls after severe thermal burns. Surg Gynecol Obstet 170(4):295-298, 1990.

5. Tasker RC: Gender differences and critical medical illness. Acta Paediatr 89(5):621-623, 2000.

6. Cunningham M, Gilkeson G: Estrogen receptors in immunity and autoimmunity. Clin Rev Allergy Immunol 40(1):66-73, 2011.

7. Lahita RG: Sex hormones and the immune system-Part 1. Human data. Baillieres Clin Rheumatol 4(1):1-12, 1990.

8. Casimir GJA, Mulier S, Hanssens L, Zylberberg K, Duchateau J: Gender differences in inflammatory markers in children. Shock 33(3): 258-262, 2010

9. Casimir GJA, Mulier S, Hanssens L, Knoop C, Ferster A, Hofman B, Duchateau J: Chronic inflammatory diseases in children are more severe in girls. Shock 34(1):23-26, 2010

10. Klein KO, Baron J, Colli MJ, McDonnell DP, Cutler GB Jr: Estrogen levels in childhood determined by an ultrasensitive recombinant cell bioassay. J Clin Invest 94(6):2475-2480, 1994.

11. Balsara SL, Faerber JA, Spinner NB, Feudtner C: Pediatric mortality in males versus females in the United States, 1999-2008. Pediatrics 132(4):631-638, 2013.

12. Spolarics Z: The X-files of inflammation: cellular mosaicism of X-linked polymorphic genes and the female advantage in the host response to injury and infection. Shock 27(6):597-604, 2007.

13. Johnston CM, Lovell FL, Leongamornlert DA, Stranger BE, Dermitzakis ET, Ross MT: Large-scale population study of human cell lines indicates that dosage compensation is virtually complete. PLoS Genet 4(1):e9, 2008.

14. Migeon BR: The role of $X$ inactivation and cellular mosaicism in women's health and sex-specific diseases. JAMA 295(12):1428-1433, 2006.

15. Carrel L, Willard HF: X-inactivation profile reveals extensive variability in Xlinked gene expression in females. Nature 434(7031):400-404, 2005.

16. Kelley MT, Walson PD, Edge JH, Cox S, Mortensen ME: Pharmacokinetics and pharmacodynamics of ibuprofen isomers and acetaminophen in febrile children. Clin Pharmacol Ther 52(2):181-189, 1992.

17. Hanada R, Leibbrandt A, Hanada T, Kitaoka S, Furuyashiki T, Fujihara H, Trichereau J, Paolino M, Qadri F, Plehm R, et al.: Central control of fever and female body temperature by RANKL/RANK. Nature 462(7272):505-509, 2009.

18. Kolaczkowska E, Kubes P: Neutrophil recruitment and function in health and inflammation. Nat Rev Immunol 13(3):159-175, 2013.

19. Lefèvre N, Corazza F, Duchateau J, Desir J, Casimir G: Sex differences in inflammatory cytokines and CD99 expression following in vitro lipopolysaccharide stimulation. Shock 38(1):37-42, 2012.

20. Wong HR, Cvijanovich N, Wheeler DS, Bigham MT, Monaco M, Odoms K, Macias WL, Williams MD: Interleukin-8 as a stratification tool for interventional trials involving pediatric septic shock. Am J Respir Crit Care Med 178(3):276-282, 2008.

21. Cartwright GE, Athens JW, Wintrobe MM: The kinetics of granulopoiesis in normal man. Blood 24:780-803, 1964.

22. Casimir GJ, Heldenbergh F, Hanssens L, Mulier S, Heinrichs C, Lefevre N, Désir J, Corazza F, Duchateau J: Gender differences and inflammation: an in vitro model of blood cells stimulation in prepubescent children. $J$ Inflamm (Lond) 7:28, 2010.

23. Ancliff PJ, Blundell MP, Cory GO, Calle Y, Worth A, Kempski H, Burns S, Jones GE, Sinclair J, Kinnon C, et al.: Two novel activating mutations in the WiskottAldrich syndrome protein result in congenital neutropenia. Blood 108(7):21822189, 2006.

24. Larsson S, Nordenson A, Glader P, Yoshihara S, Lindén A, Slinde F: A gender difference in circulating neutrophils in malnourished patients with COPD. Int $J$ Chron Obstruct Pulmon Dis 6:83-88, 2011.

25. Vigushin DM, Pepys MB, Hawkins PN: Metabolic and scintigraphic studies of radioiodinated human C-reactive protein in health and disease. J Clin Invest 91(4):1351-1357, 1993

26. Kawai T, Akira S: TLR signaling. Semin Immunol 19(1):24-32, 2007.

27. Bouman A, Schipper M, Heineman MJ, Faas MM: Gender difference in the nonspecific and specific immune response in humans. Am J Reprod Immunol 52(1): 19-26, 2004

28. Lardner A: The effects of extracellular $\mathrm{pH}$ on immune function. J Leukoc Biol 69(4):522-530, 2001.

29. Steele PM, Augustine NH, Hill HR: The effect of lactic acid on mononuclear cell secretion of proinflammatory cytokines in response to group B streptococci. J Infect Dis 177(5):1418-1421, 1998. 
30. Martínez D, Vermeulen M, Trevani A, Ceballos A, Sabatté J, Gamberale R, Alvarez ME, Salamone G, Tanos T, Coso OA, et al.: Extracellular acidosis induces neutrophil activation by a mechanism dependent on activation of phosphatidylinositol 3-kinase/Akt and ERK pathways. J Immunol 176(2):1163-1171, 2006.

31. Zampieri FG, Kellum JA, Park M, Ranzani OT, Barbeiro HV, de Souza HP, da Cruz Neto LM, da Silva FP: Relationship between acid-base status and inflammation in the critically ill. Crit Care 18(4):R154, 2014.
32. Vila Pérez D, Jordan I, Esteban E, García-Soler P, Murga V, Bonil V, Ortiz I, Flores C, Bustinza A, Cambra FJ: Prognostic factors in pediatric sepsis study, from the Spanish Society of Pediatric Intensive Care. Pediatr Infect Dis J 33(2):152-157, 2014.

33. Kellum JA: Fluid resuscitation and hyperchloremic acidosis in experimental sepsis: improved short-term survival and acid-base balance with Hextend compared with saline. Crit Care Med 30(2):300-305, 2002.
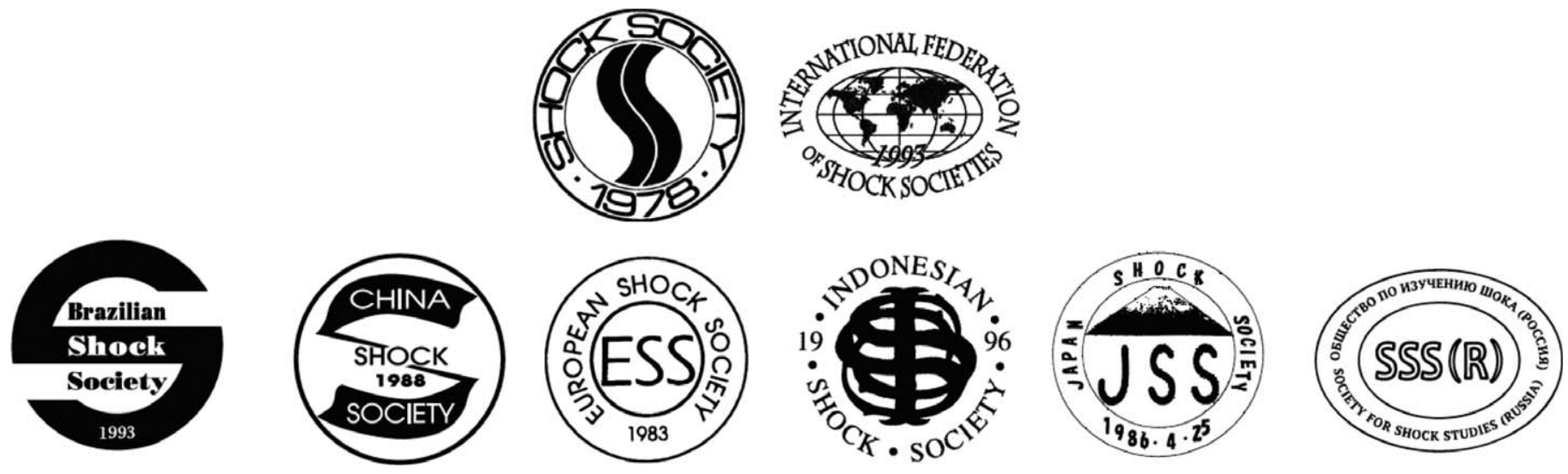

Copyright $(\odot 2016$ by the Shock Society. Unauthorized reproduction of this article is prohibited. 